\title{
EchoGéo
}

$13 \mid 2010$

Afrique, 50 ans d'indépendance : État et territoires

\section{Jaune Ciskei, Verte Hogsback}

\section{Sylvain Guyot et Anne-Laure Amilhat-Szary}

\section{(2) OpenEdition}

Journals

Édition électronique

URL : https://journals.openedition.org/echogeo/12025

DOI : 10.4000/echogeo.12025

ISSN : 1963-1197

\section{Éditeur}

Pôle de recherche pour l'organisation et la diffusion de l'information géographique (CNRS UMR 8586)

\section{Référence électronique}

Sylvain Guyot et Anne-Laure Amilhat-Szary, « Jaune Ciskei, Verte Hogsback », EchoGéo [En ligne], 13। 2010, mis en ligne le 20 septembre 2010, consulté le 03 août 2021. URL : http://

journals.openedition.org/echogeo/12025; DOI : https://doi.org/10.4000/echogeo.12025

Ce document a été généré automatiquement le 3 août 2021

EchoGéo est mis à disposition selon les termes de la licence Creative Commons Attribution - Pas d'Utilisation Commerciale - Pas de Modification 4.0 International (CC BY-NC-ND) 


\title{
Jaune Ciskei, Verte Hogsback
}

\author{
Sylvain Guyot et Anne-Laure Amilhat-Szary
}

\section{NOTE DE L'AUTEUR}

Les clichés présentés dans cet article ont été réalisés par les auteurs lors d'une mission de terrain en octobre 2008 effectuée dans le cadre du programme C2R « Gestion sociopolitique de l'environnement dans les Pays du Sud » financé par la Région Limousin et l'Université de Limoges.

Illustration 1- Vue prise de la Tyume Valley, ex-Ciskei, Afrique du Sud

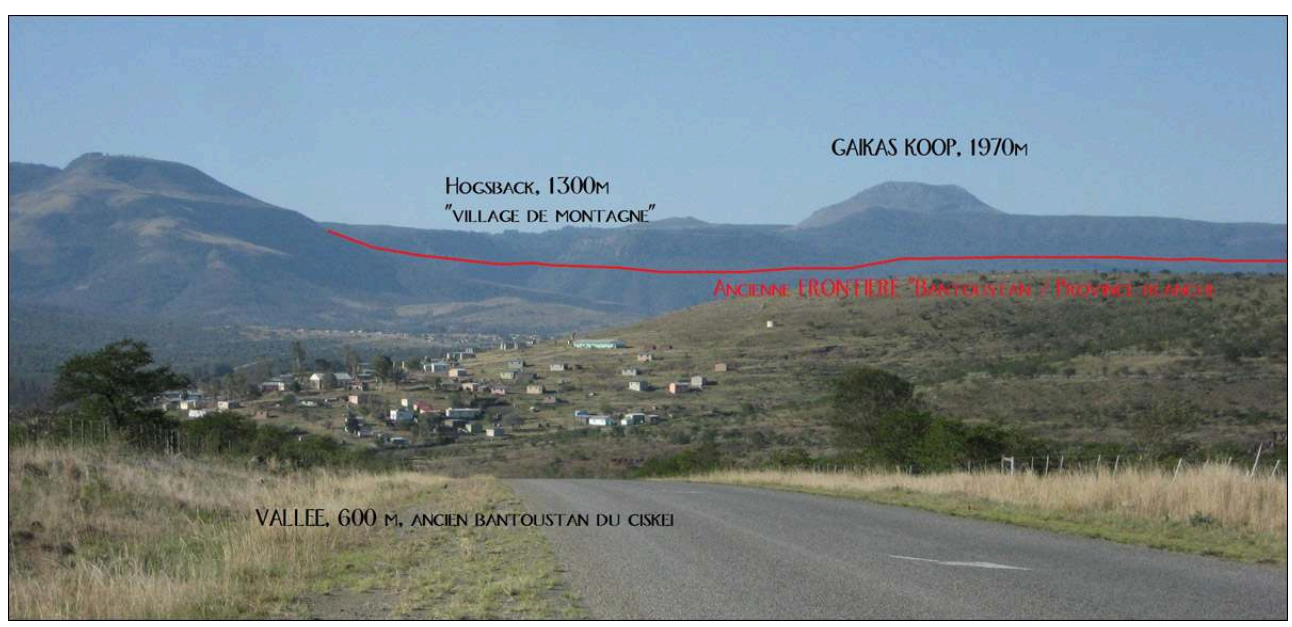

Auteurs : Anne-Laure Amilhat-Szary, Sylvain Guyot, octobre 2008. 


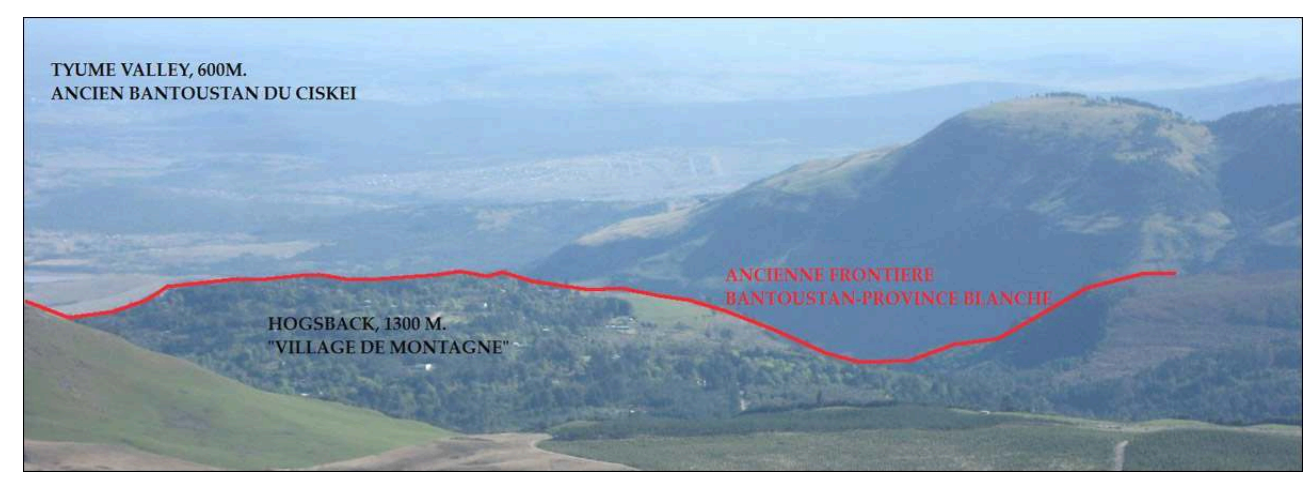

Auteurs : Anne-Laure Amilhat-Szary, Sylvain Guyot, octobre 2008.

1 La région de Hogsback dans la Province du Cap Oriental en Afrique du Sud est un terrain de recherche tout à fait stimulant pour qui veut étudier les liens entre la "fabrique de la nature » et la question des ex-limites «raciales» sud-africaines. En Afrique du Sud, la « fabrique de la nature » associe des représentations et des idéologies de la nature à une matérialité spatialisée. Mise au service de la séparation entre les différents groupes « raciaux » durant plusieurs siècles de colonisation et d'apartheid, la fabrique de la nature et sa territorialisation sont aujourd'hui invoquées et convoquées pour créer du lien entre les habitants. Pourtant, à Hogsback, les héritages du passé semblent difficiles à surmonter. Un escarpement de forêt autochtone, autrefois instrumentalisé par l'ancienne frontière "internationale » entre le Bantoustan du Ciskei et la Province du Cap, est âprement disputé entre les Noirs de la Tyume Valley et les Blancs d'Hogsback. Il fait toujours aujourd'hui office de zone tampon entre deux mondes, une vallée agricole africaine dédiée essentiellement à l'élevage et une station de montagne nichée au cœur de la forêt. Ainsi, la fabrique de la nature à Hogsback est basée sur le jardin exotique à l'européenne rappelant les racines britanniques des habitants. Une telle esthétique ne pourrait exister sans le concours d'une main d'œuvre noire habitant sur place dans des baraquements de fond de jardin. Ils réclament depuis près de 20 ans des logements décents au sein d'un nouveau village. Rien n'a pu sortir de terre en raison d'arguments environnementaux plus ou moins convaincants provenant de bureaux d'études blancs (risque d'inondation, d'incendie, de tempête etc.) et se faisant l'écho de la majorité de résidents souhaitant maintenir ce petit prolétariat africain dans l'invisibilité la plus totale. Pourtant la communauté blanche d'Hogsback n'en est pas à une contradiction près. En valorisant leurs jardins rappelant la vieille Europe, cette communauté de retraités autoproclamés écologistes se mobilise pour l'arrachage d'autres alien plants considérées comme nuisibles (les mimosas), cherche à empêcher la transhumance pluriséculaire du bétail des Noirs de la Tyume Valley mais ne milite pas pour la remise en cause des nombreux hectares de forêts commerciales de pins (autre alien pourtant !) qui constituent pourtant le paysage montagnard qualifié à leur yeux de wilderness (nature sauvage). Des liens existent pourtant entre ces différents groupes et concernent des initiatives alternatives (agriculture biologique, artisanat, etc.) et structurantes pour dynamiser le tourisme régional. 


\section{AUTEURS}

\section{SYLVAIN GUYOT}

UMR GEOLAB, Université de Limoges, sylvain.guyot@unilim.fr

ANNE-LAURE AMILHAT-SZARY

UMR PACTE, Université de Grenoble, Anne-Laure.Amilhat@ujf-grenoble.fr 